\title{
Simple apparatus for the simultaneous monitoring of central venous and mean arterial pressures in the ward
}

\author{
BARRIE J A A RONS \\ From the Thoracic Surgical Unit, Alfred Hospital, Melbourne
}

The apparatus described is used for the monitoring of venous and arterial pressures after open heart surgery and provides a means of administering drugs intravenously and of taking samples of venous or arterial blood. It has now been used on 70 consecutive cases for periods varying from one to 72 hours (average 20 hours) without any complications. The design is simple and the equipment is inexpensive. The arterial manometer is a modification of that described by Hale (1964). There is a place for its use in the management of other seriously ill patients and also during haemodialysis.

\section{THE APPARATUS}

The two manometers are mounted on a board clamped to a transfusion pole attached to the bed (Figure). The venous manometer consists of a length of clear plastic tubing mounted vertically. The arterial manometer is a standard type of anaeroid sphygmomanometer to which is attached a length of tightfitting plastic tubing containing fluid but leaving about $10 \mathrm{~cm}$. of air below the manometer. In all other respects the two sets of apparatus are similar. Each has two disposable three-way plastic stopcocks ${ }^{1}$ mounted in series. To one end is attached the source of flushing fluid and to the other the patient's manometer line. The manometer is connected to the vertically disposed side-arm of the stopcock furthest from the patient. The other stopcock is mounted so that its side-arm protrudes perpendicular to the board and is kept sterile by a plug which is only removed to allow intravenous injection or blood sampling.

For the arterial cannula we use nylon tubing of $1 \mathrm{~mm}$. internal diameter (Boots size 3 or Portex nylon intravenous cannula FG4) introduced about $5 \mathrm{~cm}$. into the artery by the Seldinger (1953) percutaneous technique. For the venous cannula we insert a fine plastic tube (Intracath. size 14) percutaneously via the external jugular vein into the superior vena cava ; occasionally tubing identical to that used for the arterial cannula is inserted into the femoral vein by

I Pharmaceal the Seldinger technique. Using appropriate connexions, each cannula is attached to $1.5 \mathrm{~m}$. of nylon tubing (Boots size 4), having a tight-fitting (16 gauge) hollow needle in its distal end. This needle is pushed on to the stopcock on the board as shown.

Maintenance of patency is achieved in each instance by continuous infusion. The venous manometer virtually becomes a side-arm in a standard intravenous infusion which is only interrupted intermittently to record the venous pressure. We add 1 unit heparin/ $\mathrm{ml}$. (10 mg./1.) to this intravenous fluid. To keep the arterial cannula patent we use an infusion of $5 \%$ dextrose containing 4 units heparin $/ \mathrm{ml}$. (40 mg./1.) administered by a pressure of $160 \mathrm{~mm} . \mathrm{Hg}$ through a standard microdrip infusion set controlled by a reliable, easily adjusted screw clamp (Aarons and Merei, 1965). We set this to run at $2 \mathrm{ml}$./hour, and have found this to be adequate to maintain patency. After taking a sample of arterial blood the line is flushed with $5 \mathrm{ml}$. of the same fluid from a syringe via the side-arm from which the blood was taken. This system entails a minimal risk of arterial air embolism. This risk may be completely eliminated by using a plastic bag of fluid with a sphygmomanometer cuff wrapped around it.

Because of the resistance in the lines and inertia of the manometer, a 'mean' arterial pressure a little lower than the calculated mean is obtained. Small variations in this 'mean' pressure are readily detected, and may be regarded as representing similar changes in the true mean pressure. The purpose of monitoring pressures is to detect change, and this apparatus fulfils that purpose.

The pressures are easily read. The stopcocks immediately below the manometers are turned to connect the patient to the manometer (this simultaneously stops the infusions). The patency of the cannulae is shown by an oscillation of the needle of the arterial manometer and a respiratory fluctuation of the surface of the fluid in the venous manometer. When the recordings have stabilized, the stopcocks are returned to their original positions, allowing continuous infusion. The mean arterial pressure is read directly on the dial. The central venous pressure is read as the height of the fluid in the tube above the manubrio-sternal angle. In practice it is read on the 


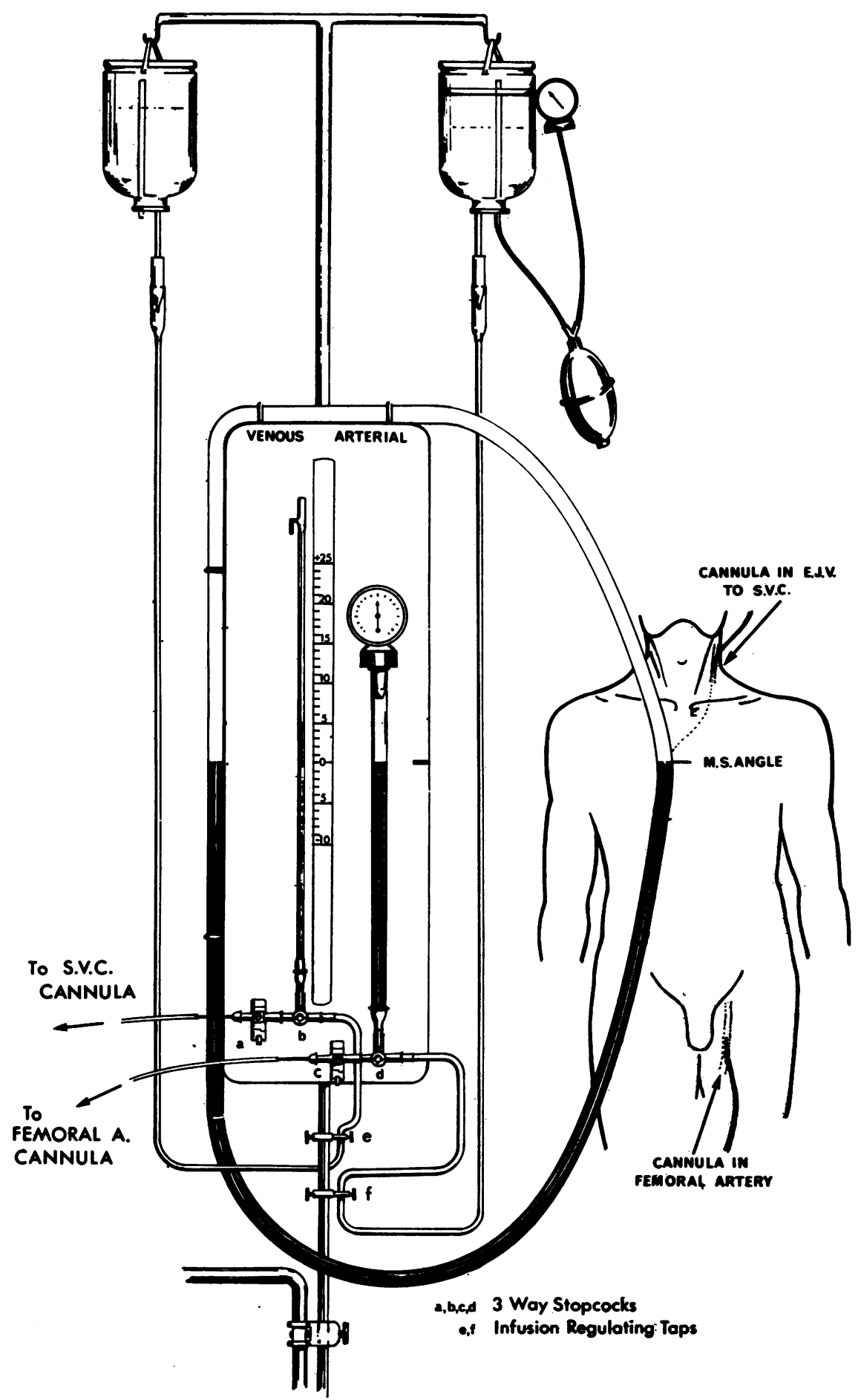

FIGURE. Simple apparatus for the simultaneous monitoring of central venous and mean arterial pressures in the ward. 
sliding scale next to the manometer. The zero of this scale is set at the level of the manubrio-sternal angle by using a levelling tube and is checked at frequent intervals and after moving the patient. This levelling tube consists of a 3-metre length of clear plastic tubing (Portex Boots size 12 H.E.) half-filled with coloured water and joined into a closed loop. One portion is attached to the venous side of the board and the other is free so that it can be placed against the patient's chest and adjusted until the level of fluid in it is level with the manubrio-sternal angle. The sliding scale on the board is then moved to bring the zero to the level of the fluid in the adjacent part of the levelling tube. A coloured line drawn vertically on the board immediately behind the venous manometer tube simplifies reading, since the fluid-filled part of the tube magnifies the line and appears as a coloured column of fluid.

The anaeroid manometers and sphygmomanometer bulb are sterilized in formalin vapour for 24 hours. All other parts are autoclaved or are available sterile in packets from the manufacturers (e.g., stopcocks). All tubing and stopcocks are discarded after use.
Apart from the value of having a m mthod of checking clinically recordable pressures, this apparatus has been of great value in many patients in whom arterial pressure has not been recordable by other means. In such patients it has been a very useful guide to therapy.

\section{REFERENCES}

Aarons, B. J., and Merei, F. (1965). A reliable clamp for controlling rate of of intravascular infusions. Lancet. In the press.

Hale D. (1964). Arterial and venous pressure readings during openheart operations. Cleveland Clin. Quart., 31, 45.

Seldinger, S. I. (1953). Catheter replacement of the needle in percutaneous arteriography. Acta radiol. (Stockh.), 39, 368.

\section{ADDENDUM}

Since this paper was written the apparatus has been used in a further 30 cases without complication. In one very sick patient with electrolyte and respiratory problems, the arterial cannula was left in situ for analysis. There was no evidence of embolism or infection and removal of the cannula was uneventful. 